\title{
Retrospective single-surgeon study of outcomes after laparoendoscopic single-site cholecystectomy and sigmoidectomy
}

\author{
A. Smirnoff ${ }^{1} \cdot$ L. de Poncheville ${ }^{2}$ C. Allix-Béguec ${ }^{3} \cdot$ P.-Y. Lefant ${ }^{1}$. \\ E. Drapier ${ }^{2}$
}

Received: 18 September 2014/ Accepted: 2 October 2015/Published online: 27 October 2015

(c) The Author(s) 2015. This article is published with open access at Springerlink.com

\begin{abstract}
Purpose Laparoendoscopic single-site (LESS) surgery is performed through a single port but requires a larger incision than conventional laparoscopy, which theoretically increases the risk of laparoscopic port hernia. Our primary objective is to determine the trocar site hernia rate among our patients.

Methods This retrospective study is based on the analysis of demographic, intraoperative, and postoperative data of 219 patients who underwent cholecystectomy or sigmoidectomy by LESS surgery between December 1st, 2009 and November 30th, 2012.

Results Cholecystectomy and sigmoidectomy LESS surgery were performed on 190 and 29 patients, respectively. Three patients developed a trocar site hernia within a median follow-up time of 34.7 months. Eleven patients were obese, 20 had a history of abdominal surgery, and 20 had a preoperative umbilical hernia but none of them developed a trocar site hernia, neither did the 11 subsequently pregnant women. Significant association was found between preoperative umbilical hernia and early complications including incisional cellulitis and hematoma.

Conclusions A rate of $1.4 \%$ of trocar site hernia was observed in our study population. This rate is similar to the
\end{abstract}

A. Smirnoff

alexandre.smirnoff@ch-larochelle.fr

1 Visceral Surgery Department, Groupe Hospitalier de la Rochelle Ré Aunis, rue du Dr Schweitzer,

17000 La Rochelle, France

2 Clinique du Mail, 96 Allée du Mail, 17000 La Rochelle, France

3 Clinical Research Unit, Groupe Hospitalier de la Rochelle Ré Aunis, rue du Dr Schweitzer, 17000 La Rochelle, France one reported after conventional laparoscopy. Peri-umbilical incision, longer than that with conventional laparoscopy, allowed better preexisting hernia handling, made anatomical closing easier among obese patients, and facilitated specimen extraction thus limiting traumatic operations.

Keywords Laparoscopy - Hernia · Trocar · Cholecystectomy $\cdot$ Sigmoidectomy

\section{Introduction}

The main advantage of laparoscopic surgery is to better preserve abdominal wall integrity, in comparison with laparotomy. However, specific morbidity is linked to insertion of trocars of $3.5-15 \mathrm{~mm}$ through abdominal wall. It mainly consists in incisional cellulitis and hematoma, and less frequently in trocar site hernia. Several publications studied trocar site hernia occurrences in order to identify clinical warnings and prevention strategies for such complications. A review based on 16 studies from the past 10 years and including 20,281 patients who underwent laparoscopic surgery (gastrointestinal, urological, gynecological or vascular) showed a rate of $0.7 \%$ of laparoscopic port hernias [1]. Two studies about laparoscopic colorectal surgery reported an extraction site incisional hernia rate of 7.8 and $6 \%$, respectively [2,3]. A paper focusing on laparoscopic gastrointestinal surgery reviewed 18 studies including 11,699 patients and showed a trocar port hernia rate of $0.74 \%$ [4]. Morbidity and more particularly laparoscopic port hernia rate are thus associated with trocar number and with incision size larger than $5 \mathrm{~mm}[5,6]$, and it is now well known that incision equal or larger than $10 \mathrm{~mm}$ length should be closed with extra care $[4,7,8]$. Laparoendoscopic single-site (LESS) surgery is based on a 
single port but requires a larger incision. The single larger incision, that can also be the extraction site of operating specimen, theoretically increases the risk of laparoscopic port hernia. Therefore, the objectives of the present study are to determine the trocar site hernia rate and to identify its predictive factors among a cohort of patients who underwent cholecystectomy and sigmoidectomy by LESS surgery, and to compare corresponding results with published ones for conventional laparoscopy and for LESS surgery.

\section{Materials and methods}

\section{Statement of human rights}

This study did not intrude with patient's care and all patients included in this study have been informed of the research and of their right to oppose the use of their data.

\section{Study design and patient selection}

The present study is a retrospective analysis of patients who underwent cholecystectomy and sigmoidectomy by LESS surgery in the visceral surgery department at Groupe Hospitalier de la Rochelle Ré Aunis, France in order to determine the trocar site hernia rate. Eligible patients had a scheduled LESS surgery, in respect with preoperative status defined according to the Physical Status Classification I to III as classified by the American Society of Anesthesiology, between December 1st, 2009 and November 30th, 2012. Demographic, intraoperative, and postoperative data of 219 patients treated by the same surgeon were collected and entered into a de-identified database. Nine patients were not included in the database as their follow-up data were not available ( 2 deceased, and 7 were lost to followup). Reported data included age, gender, body mass index, previous abdominal surgery, diagnosis, incision length, operative time, use of additional instrument, preoperative umbilical hernia, postoperative hospital stay, early and late complications, and pregnancy after surgery. Follow-up data corresponded to patient's consultation at day 15 , day 30 , and 1 year later, and were collected by phone during a follow-up campaign performed over the end of year 2013. All patients were examined by the same clinician. Phone call included the following question: have you noticed something in the area of the trocar site like a bulge, a burn, gurgle, pain, or discomfort especially while doing Valsalva maneuver. In case of doubt during the clinical or phone call examination, ultrasonography of the access site was performed. All related serious adverse events requiring a therapeutic response were recorded as postoperative morbidity. Early complications were considered to happen within 1 month after the surgery and late complications later on.

\section{Operative technique}

A 2- or a 3-cm arcuate incision was performed at the umbilicus upper edge for cholecystectomy and lower edge for sigmoidectomy. The facial level was incised transversely over a length of 25 or $30 \mathrm{~mm}$ for cholecystectomy and sigmoidectomy, respectively. The SILS ${ }^{\circledR}$ port system (Covidien, Mansfield, USA) was used for cholecystectomy and single port Gelpoint ${ }^{\circledR}$ (Applied Medical Systems, Rancho Santa Margarita, CAR), that is fitted with a wound protector, was used for sigmoidectomy. Intraoperative cholangiography was performed for 18 patients. A $50-\mathrm{cm}$ long, $30^{\circ}, 5-\mathrm{mm}$ diameter, laparoscope (Storz, Stuttgart, Germany); straight laparoscopic instruments (coagulating device, scissors and graspers); and in case of sigmoidectomy a LigaSure ${ }^{\mathrm{TM}} \mathrm{V}$ vessel sealing instrument (Valleylab, Boulder, Colorado, USA) were used. Operating time was recorded starting from umbilical incision up to its closing. The gallbladder was extracted using an EndoCatch bag (Covidien, Mansfield, USA).The sigmoidectomy specimen was pulled out through the wound protector. The colon was returned to the peritoneal cavity after positioning an anvil for EEA anastomosis (EEA ${ }^{\mathrm{TM}}$ 31-mm circular stapler from Covidien, Mansfield, USA).

The abdominal wall fascia was closed by two figures of eight sutures of Vicryl 0 (Ethicon Endo-Surgery (Europe) $\mathrm{GmbH}$, Norderstedt, Germany) or using four simple interrupted stitches of vicryl 2 (Ethicon Endo-Surgery (Europe) GmbH, Norderstedt, Germany) for cholecystectomy and sigmoidectomy, respectively.

\section{Statistics}

The primary objective was the estimation of laparoscopic port hernia rate. Secondary objectives were to report on other adverse events and potential consequences on subsequent pregnancies. A descriptive analysis of the data is reported. Association between five factors (age, body mass index, history of previous abdominal surgery, preoperative umbilical hernia, and operative time) and the apparition of post-cholecystectomy complications was studied. Bivariate ORs and $95 \%$ confidence intervals were estimated.

\section{Results}

Among the 219 patients included in the study, $66.2 \%$ were female, the median age was 57 years old, and the median body mass index was $24.4 \mathrm{~kg} / \mathrm{m}^{2}$ (Table 1). Previous abdominal surgery was registered for $9.1 \%$ of the patients, 
Table 1 Demographics and clinical characteristics of study patients

\begin{tabular}{lccc}
\hline & $\begin{array}{l}\text { Cholecystectomy } \\
(n=190)\end{array}$ & $\begin{array}{l}\text { Sigmoidectomy } \\
(n=29)\end{array}$ & $\begin{array}{l}\text { Total } \\
(n=219)\end{array}$ \\
\hline Median age, years (range) & $54(14-88)$ & $64(40-92)$ & $57(14-92)$ \\
Gender & $57(30 \%)$ & $17(58.6 \%)$ & $74(33.8 \%)$ \\
Male & $133(70 \%)$ & $12(41.4 \%)$ & $145(66.2 \%)$ \\
Female & $24.3(15.8-44.9)$ & $25(18.7-57.1)$ & $24.4(15.8-57.1)$ \\
Median BMI, kg/m ${ }^{2}$ (range) & $108(56.8 \%)$ & $14(48.3 \%)$ & $122(55.7 \%)$ \\
Normal $\leq 24.9$ & $73(38.4 \%)$ & $13(44.8 \%)$ & $86(39.3 \%)$ \\
Overweight $25.0-29.9$ & $9(4.7 \%)$ & $2(6.9 \%)$ & $11(5.0 \%)$ \\
Obese $\geq 30.0$ & $6(3.2 \%)$ & $3(10.3 \%)$ & $9(4.1 \%)$ \\
Previous abdominal surgery & $10(5.3 \%)$ & $1(3.4 \%)$ & $11(5.0 \%)$ \\
Laparotomy & $136(71.6 \%)$ & & $136(62.1 \%)$ \\
Laparoscopy & $47(24.7 \%)$ & & $47(21.5 \%)$ \\
Diagnosis & $7(3.7 \%)$ & & $7(3.2 \%)$ \\
Biliary colic & $16(8.4 \%)$ & $29(100 \%)$ & $29(13.2 \%)$ \\
Acute cholecystitis & & $4(13.8 \%)$ & $20(9.1 \%)$ \\
Acute pancreatitis & & & \\
Diverticular disease & Preoperative umbilical hernia & & \\
\hline
\end{tabular}

$B M I$ body mass index
9 had a laparotomy with umbilical incision and 11 had a laparoscopy using a 12-mm trocar in umbilical position. Diagnosis of biliary colic, acute cholecystitis, and acute pancreatitis in 136,47 , and 7 patients, respectively, led up to a scheduled cholecystectomy. Twenty-nine patients underwent sigmoidectomy for recurrent diverticular disease. Preoperative umbilical hernia has been observed in 20 patients, 16 and 4 who underwent a cholecystectomy and sigmoidectomy, respectively.

The median operating time was 34.5 and 118 min for cholecystectomy and for sigmoidectomy, respectively (Table 2). An incision of $20 \mathrm{~mm}$ length was made for cholecystectomy and of $30 \mathrm{~mm}$ length for sigmoidectomy. No subsequent open surgery was required for any of the patients and none of the patient developed perioperative access-site complication. However, due to diverticulitis specimen extraction difficulty during sigmoidectomy, 8 patients required incision enlargement (5 and $10 \mathrm{~mm}$ widening for 4 and 4 patients, respectively). Median postoperative hospital stay varied from 1 day for patients who underwent cholecystectomy to 5 days for patients who underwent sigmoidectomy. Early complications occurred in 12 patients and consisted in umbilical incisional hematoma $(2.7 \%)$, umbilical incisional cellulitis $(2.3 \%)$ handled by local care at patient's home, and 1 case of hemoperitoneum that occurred after cholecystectomy and required a secondary surgical revision in order to wash the vesicular area. Late complication, consisting in laparoscopic port hernia, was detected in three patients $(1.4 \%)$ during follow-up. All three were detected by physical examination, while 14 doubts led to verification by ultrasonography but were not confirmed as trocar port hernia. One case happened 4 months after a cholecystectomy, and the two others happened 8 months after a sigmoidectomy. Clinical signs were an umbilical bud without pain or occlusive syndrome. The three patients underwent a secondary open surgery. Hernias were repaired using an intraperitoneal underlay technique utilizing a bilayer prosthetic mesh.

No significant association was found between postoperative complications and patient's age, body mass index, previous abdominal surgery, and operative time (Table 3). However, an association between early postoperative complications and pre-existing umbilical hernia has been observed among patients who underwent cholecystectomy. Involved complications consisted in umbilical incisional hematoma and cellulitis.

\section{Discussion}

The laparoscopic port hernia rate observed in our study is similar to that usually reported in conventional laparoscopy, and similar results have recently been published in LESS gynecological surgery with a trocar site hernia rate of 0.5 and $0.6 \%[9,10]$. In a multicentric study about cholecystectomy using LESS surgery, Curcillo et al. report a $0 \%$ rate [11], while in a monocentric study, Krajinovic et al. report a $2 \%$ rate [12]. In LESS colorectal surgery, 
Table 2 Primary and secondary outcomes
Table 3 Bivariate analysis of association between postoperative complications and selected predictors for patients who underwent cholecystectomy

\begin{tabular}{lccr}
\hline & $\begin{array}{l}\text { Cholecystectomy } \\
(n=190)\end{array}$ & $\begin{array}{l}\text { Sigmoidectomy } \\
(n=29)\end{array}$ & $\begin{array}{c}\text { Total } \\
(n=219)\end{array}$ \\
\hline Primary outcomes & & & \\
$\quad$ Median length of incision, mm (range) & $20(19-21)$ & $30(30-40)$ & $20(20-40)$ \\
Incision enlargement & $0(0.0 \%)$ & $8(27.6 \%)$ & $8(3.6 \%)$ \\
Median operating time, min (range) & $34.5(18-97)$ & $118(70-217)$ & $35(18-217)$ \\
Additional instrument & $5(2.6 \%)$ & $2(6.9 \%)$ & $7(3.2 \%)$ \\
Secondary outcomes & $1(0.4-8)$ & $5(1-9)$ & $1(0.4-9)$ \\
Postoperative hospital stay, days (range) & $34.7(13-49)$ & $30.2(13-42)$ & $34.4(13-49)$ \\
Median follow-up time, months (range) & & $1(3.5 \%)$ & $6(2.7 \%)$ \\
Early complications & $5(2.6 \%)$ & $0(0 \%)$ & $1(0.5 \%)$ \\
$\quad$ Hematoma & $1(0.5 \%)$ & $1(3.5 \%)$ & $5(2.3 \%)$ \\
$\quad$ Hemoperitoneum & $4(2.1 \%)$ & & $3(1.4 \%)$ \\
$\quad$ Wound complication & & $2(6.9 \%)$ & $13(5.9 \%)$ \\
Late complications & $1(0.5 \%)$ & $7(24.1 \%)$ & $11(5.0 \%)$ \\
$\quad$ Laparoscopic port hernia & $22(11.5 \%)$ & $0(0.0 \%)$ & \\
Overall morbidity & $11(5.8 \%)$ & & \\
Pregnancy & & & \\
\hline
\end{tabular}

\begin{tabular}{|c|c|c|c|c|}
\hline & Patients & Postoperative complication (\%) & OR $(95 \% \mathrm{CI})$ & $p$ value \\
\hline \multicolumn{5}{|l|}{ Age (years) } \\
\hline $0-59$ & 112 & $8(7 \%)$ & 1.0 & \multirow[t]{2}{*}{0.182} \\
\hline$\geq 60$ & 78 & $2(3 \%)$ & $0.3(0.1-1.6)$ & \\
\hline \multicolumn{5}{|l|}{ BMI $\left(\mathrm{kg} / \mathrm{m}^{2}\right)$} \\
\hline Normal & 108 & $3(3 \%)$ & 1.0 & \multirow[t]{2}{*}{0.094} \\
\hline Overweight and obese & 82 & $7(9 \%)$ & $3.3(0.8-13)$ & \\
\hline \multicolumn{5}{|c|}{ Previous abdominal surgery } \\
\hline No & 174 & $9(5 \%)$ & 1.0 & \multirow[t]{2}{*}{0.854} \\
\hline Yes & 16 & $1(6 \%)$ & $1.2(0.1-10.3)$ & \\
\hline \multicolumn{5}{|c|}{ Preoperative umbilical hernia } \\
\hline No & 174 & $6(3 \%)$ & 1.0 & \multirow[t]{2}{*}{0.002} \\
\hline Yes & 16 & $4(25 \%)$ & $9.3(2.3-37.6)$ & \\
\hline \multicolumn{5}{|l|}{ Operative time (min) } \\
\hline$\leq 30$ & 76 & $2(3 \%)$ & 1.0 & \multirow[t]{2}{*}{0.202} \\
\hline$>30$ & 114 & $8(7 \%)$ & $2.8(0.6-13.5)$ & \\
\hline
\end{tabular}

Postoperative complications include hematoma, hemoperitoneum, wound complication, and laparoscopic port hernia

$O R$ odds ratio, $C I$ confidence interval, $B M I$ body mass index
Podolsky et al. report a rate of $1.6 \%$ [13], and in LESS appendectomy Buckley et al. report a $0.59 \%$ rate [14]. To our knowledge, only one prospective, multicentric, randomized study reports a significantly increased rate of laparoscopic port hernia after LESS surgery in comparison with conventional laparoscopy for cholecystectomy (1.2 vs $8.4 \%, p=0.03$ ) [15].

In the literature, most trocar port hernias were identified within the first year after surgery [16, 17]. However, complications could occur later on, with warning clinical signs ranging from simple abdominal bud, associated or not with pain, to true occlusive syndrome [18]. In our study, one case happened 4 months after a cholecystectomy and the 2 others happened 8 months after a sigmoidectomy. None of these laparoscopic port hernias were associated with intestinal incarceration. Moreover, among patients who underwent a cholecystectomy, eleven carried out a pregnancy to term (one got pregnant twice) within 4 years following the surgery and none of them developed a trocar site hernia. 
Although obesity is considered a classical risk factor for laparoscopic port hernia, none of the 11 patients with a body mass index above $30 \mathrm{~kg} / \mathrm{m}^{2}$ developed such complication in our study. It is noteworthy that the quality of the parietal wall closure is increased thanks to easier access related to LESS incision size [9-11]. Moreover, optimal air expiry through this larger port allows avoiding the effect of visceral mass and omentum "expulsion" along with remaining carbon dioxide as described by Duron et al. [19]. As it was feasible, and as recommended by Montz et al. [18], systematic closure of peritoneum plane and muscle fascia was performed. Indeed, lack of closure of posterior plane seems to increase trocar site hernia risk [20].

In conventional laparoscopy, laparoscopic port hernia risk is increased by the presence of preoperative umbilical hernia [21]. Such anomaly has been observed among 20 of our patients $(9.1 \%)$. Patients with or without preoperative hernia were handled the same way: the closure has been done under direct vision, incorporating all layers of the abdominal wall including the peritoneum. Even though an association between early postoperative complication and pre-existing umbilical hernia has been observed among patients who underwent cholecystectomy, none of them developed a laparoscopic port hernia, and neither did the four patients with pre-existing umbilical hernia who underwent a sigmoidectomy. We believe that incision length in laparoscopy single-site surgery offers a better view of the anatomical region, and thus enables easier detection and handling of pre-existing umbilical hernia.

Iterative introduction of trocars and secondary enlargement of orifice for device extraction during conventional laparoscopy have been involved with incisional cellulitis, hematoma, and trocar site hernia [22]. During LESS surgery for cholecystectomy, none of these additional interventions was necessary even in case of large gallstone. Due to diverticulitis specimen extraction difficulty during sigmoidectomy, 8 patients required incision enlargement (5 and $10 \mathrm{~mm}$ widening for 4 and 4 patients, respectively). None of the corresponding patients developed subsequent laparoscopic port hernia, but one patient had both hematoma and wound infection.

Leibl et al. emphasized the traumatic nature of conventional laparoscopy using sharp cutting trocar cannula systems which cut tissue in comparison to blunt conical trocar cannula systems that dilate tissue [23]. The use of the first procedure is more associated with trocar site hernia $(1.83 \%)$ than the second one $(0.17 \%)$. We believe that the single incision made for positioning a single port is like an incision done by a sharp cutting trocar cannula system and therefore theoretically increases trocar site hernia risk. However, to our knowledge, no study analyses the effect of differently shaped devices for LESS surgery on parietal trauma.
In conclusion, despite a higher theoretical risk of trocar site hernia with LESS surgery, the results obtained in our study show that trocar site hernia rate was similar to the rate observed after conventional laparoscopy. Peri-umbilical incision, longer than that with conventional laparoscopy, allowed better pre-existing hernia handling and made anatomical closing easier among obese patients. Specimen retrieval was also facilitated thus limiting traumatic operations. LESS surgery seems suitable for patients concerned with esthetic integrity and for women seeking pregnancy. However, these results need to be completed by further studies providing longer follow-up time and comparing different marketed mono trocar devices.

\section{Compliance with ethical standards}

Conflict of interest Alexandre Smirnoff, Loïc de Poncheville, Caroline Allix-Béguec, Pierre-Yves Lefant, and Eric Drapier declare no conflict of interest.

Open Access This article is distributed under the terms of the Creative Commons Attribution-NonCommercial 4.0 International License (http://creativecommons.org/licenses/by-nc/4.0/), which permits any noncommercial use, distribution, and reproduction in any medium, provided you give appropriate credit to the original author(s) and the source, provide a link to the Creative Commons license, and indicate if changes were made.

\section{References}

1. Le Huu Nho R, Mege D, Ouaïssi M, Sielezneff I, Sastre B (2012) Incidence and prevention of ventral incisional hernia. J Visc Surg 149(5 Suppl):e3-e14

2. Singh R, Omiccioli A, Hegge S, McKinley C (2008) Does the extraction-site location in laparoscopic colorectal surgery have an impact on incisional hernia rates? Surg Endosc 22(12):2596-2600. doi:10.1007/s00464-008-9845-8

3. Skipworth JR, Khan Y, Motson RW, Arulampalam TH, Engledow AH (2010) Incisional hernia rates following laparoscopic colorectal resection. Int J Surg 8(6):470-473. doi:10.1016/j.ijsu. 2010.06.008

4. Owens M, Barry M, Janjua AZ, Winter DC (2011) A systematic review of laparoscopic port site hernias in gastrointestinal surgery. Surgeon 9(4):218-224. doi:10.1016/j.surge.2011.01.003

5. Fuller J, Ashar BS, Carey-Corrado J (2005) Trocar-associated injuries and fatalities: an analysis of 1399 reports to the FDA. J Minim Invasive Gynecol 12(4):302-307. doi:10.1016/j.jmig. 2005.05.008

6. Neudecker J, Sauerland S, Neugebauer E et al (2002) The European Association for Endoscopic Surgery clinical practice guideline on the pneumoperitoneum for laparoscopic surgery. Surg Endosc 16(7):1121-1143. doi:10.1007/s00464-001-9166-7

7. Shah A, Moftah M, Hadi Nahar Al-Furaji H, Cahill RA (2014) Standardized technique for single port laparoscopic ileostomy and colostomy. Colorectal Dis 16(7):O248-O252. doi:10.1111/ codi. 12601

8. Comajuncosas J, Hermoso J, Gris P, Jimeno J, Orbeal R, Vallverdú H, López Negre JL, Urgellés J, Estalella L, Parés D (2014) Risk factors for umbilical trocar site incisional hernia in laparoscopic cholecystectomy: a prospective 3-year follow-up study. Am J Surg 207(1):1-6 
9. Gunderson CC, Knight J, Ybanez-Morano J et al (2012) The risk of umbilical hernia and other complications with laparoendoscopic single-site surgery. J Minim Invasive Gynecol 19(1):40-45. doi:10.1016/j.jmig.2011.09.002

10. Park JY, Kim TJ, Kang HJ et al (2013) Laparoendoscopic single site (LESS) surgery in benign gynecology: perioperative and late complications of 515 cases. Eur J Obstet Gynecol Reprod Biol 167(2):215-218. doi:10.1016/j.ejogrb.2012.11.027

11. Curcillo PG, Wu AS, Podolsky ER et al (2010) Single-port-access (SPA) cholecystectomy: a multi-institutional report of the first 297 cases. Surg Endosc 24(8):1854-1860. doi:10.1007/ s00464-009-0856-x

12. Krajinovic K, Ickrath P, Germer CT, Reibetanz J (2011) Trocarsite hernia after single-port cholecystectomy: not an exceptional complication? J Laparoendosc Adv Surg Tech A 21(10):919-921. doi:10.1089/lap.2011.0292

13. Podolsky ER, Curcillo PG (2010) Single port access (SPA) surgery-a 24-month experience. J Gastrointest Surg 14(5):759-767. doi:10.1007/s11605-009-1081-6

14. Buckley FP, Vassaur H, Monsivais S, Jupiter D, Watson R, Eckford J (2014) Single-incision laparoscopic appendectomy versus traditional three-port laparoscopic appendectomy: an analysis of outcomes at a single institution. Surg Endosc 28(2):626-630. doi:10.1007/s00464-013-3219-6

15. Marks JM, Phillips MS, Tacchino R et al (2013) Single-incision laparoscopic cholecystectomy is associated with improved cosmesis scoring at the cost of significantly higher hernia rates: 1-year results of a prospective randomized, multicenter, singleblinded trial of traditional multiport laparoscopic cholecystectomy vs single-incision laparoscopic cholecystectomy. J Am Coll
Surg 216(6):1037-1047. doi:10.1016/j.jamcollsurg.2013.02.024 discussion $\mathbf{4 7 - 4 8}$

16. Tonouchi H, Ohmori Y, Kobayashi M, Kusunoki M (2004) Trocar site hernia. Arch Surg 139(11):1248-1256. doi:10.1001/ archsurg.139.11.1248

17. Johnson WH, Fecher AM, McMahon RL, Grant JP, Pryor AD (2006) VersaStep trocar hernia rate in unclosed fascial defects in bariatric patients. Surg Endosc 20(10):1584-1586. doi:10.1007/ s00464-005-0747-8

18. Montz FJ, Holschneider CH, Munro MG (1994) Incisional hernia following laparoscopy: a survey of the American Association of Gynecologic Laparoscopists. Obstet Gynecol 84(5):881-884

19. Duron JJ, Hay JM, Msika S et al (2000) Prevalence and mechanisms of small intestinal obstruction following laparoscopic abdominal surgery: a retrospective multicenter study. French Association for Surgical Research. Arch Surg 135(2):208-212

20. Velasco JM, Vallina VL, Bonomo SR, Hieken TJ (1998) Postlaparoscopic small bowel obstruction. Rethinking its management. Surg Endosc 12(8):1043-1045

21. Azurin DJ, Go LS, Arroyo LR, Kirkland ML (1995) Trocar site herniation following laparoscopic cholecystectomy and the significance of an incidental preexisting umbilical hernia. Am Surg 61(8):718-720

22. Nassar AH, Ashkar KA, Rashed AA, Abdulmoneum MG (1997) Laparoscopic cholecystectomy and the umbilicus. Br J Surg 84(5):630-633

23. Leibl BJ, Schmedt CG, Schwarz J, Kraft K, Bittner R (1999) Laparoscopic surgery complications associated with trocar tip design: review of literature and own results. J Laparoendosc Adv Surg Tech A 9(2):135-140 